\title{
Trabalhando com a história de vida: percalços de uma pesquisa(dora?)
}

\author{
WORKING WITH THE HISTORY OF LIFE - A RESEARCH(ER'S) MISHAPS \\ TRABAJANDO CON HISTORIA DE VIDA- DIFICULTADES DE UNA INVESTIGADORA
}

\author{
Thelma Spindola ${ }^{1}$, Rosângela da Silva Santos ${ }^{2}$
}

\author{
RESUMO \\ Trata-se de um estudo de \\ natureza qualitativa, cuja \\ autora relata a sua \\ experiência na realização da \\ tese de Doutorado pelo \\ método de História de Vida. \\ Descreve a abordagem \\ metodológica, explicitando a \\ técnica para a coleta e a \\ análise dos relatos bem como \\ as eventuais dificuldades que \\ possam surgir durante a \\ realização da pesquisa. \\ Argumenta que esse método \\ possibilita a aproximação \\ entre o pesquisador e os \\ sujeitos. Destaca a \\ necessidade de se incluir a \\ dimensão subjetiva do \\ cuidado na prestação de \\ assistência à clientela.
}

\section{PALAVRAS-CHAVE}

História. Vida. Pesquisa qualitativa. Pesquisa metodológica em enfermagem.

\author{
ABSTRACT \\ In this study, characterized as \\ a qualitative one, whose \\ author tells about her \\ experience when \\ accomplishing her Doctorate \\ thesis for the History of life \\ method. She describes the \\ methodological approach, \\ turning explicit the collection \\ and the report analysis \\ technique as well as the \\ incidental difficulties that may \\ turn up during the research \\ completion. She concludes that \\ this method turns the \\ approach among the \\ researcher and the individuals \\ feasible. It points out the need \\ to include the subjective \\ dimension of the care in the \\ assistance rendered to the \\ clientele.
}

\section{KEYWORDS}

History. Life.

Qualitative research.

Nursing methodology

research.

\section{RESUMEN}

Se trata de un estudio de una naturaleza cualitativa, cuya autora relata su experiéncia en la realización de la teses de Doctorado por el método de historia de vida. Describe un tratamiento metodológico, explicando la técnica para la colecta y el análisis de los relatos bien como las eventuales dificultades que pueden surgir durante la realización de la investigación. Concluye que el método posibilita una aproximación entre el investigador y los sujetos. Destaca la necesidad de incluyir la dimensión subjetiva del cuidado en la prestación de asisténcia a la clientela.

\section{PALABRAS-CLAVE}

Historia. Vida. Investigación cualitativa. Investigación metodologica en enfermeria.
1 Professora Adjunto da Faculdade de Enfermagem da Universidade do Estado do Rio de Janeiro (UERJ). Enfermeira do HUGG da Universidade do Rio de Janeiro. spindola@centroin.com.br

2 Professora Titular do Departamento de Enfermagem Materno-Infantil. 
Thelma Spindola

Rosângela da Silva Santos

\section{INTRODUÇÃO}

A realização de uma pesquisa envolve uma série de aspectos: disponibilidade do pesquisador, aderência ao objeto estudado, interesse e um certo envolvimento entre pesquisador e pesquisa. Assim sendo, é necessário, não somente que o pesquisador tenha uma espécie de mola propulsora, seja interesse particular seja exigência de algum curso (graduação, pós-graduação e outros).

Nesse sentido, é recomendado ${ }^{(1)}$ quatro regras para a escolha do tema, quais sejam: que responda aos interesses do candidato (em nível de suas leituras, atitude política, cultural ou religiosa); que as fontes de consulta sejam acessíveis; que as fontes de consulta sejam manejáveis (alcance cultural do candidato) e, finalmente, que o quadro metodológico da pesquisa esteja ao alcance da experiência do candidato. Acreditamos que quando esses aspectos não são atendidos o desenvolvimento da pesquisa torna-se bem mais difícil e penoso.

Reforçando esse pensamento é afirma$\mathrm{do}^{(2)} \mathrm{em}$ estudos sobre pesquisa qualitativa em Ciências Sociais, que a escolha de um assunto não surge espontaneamente, é decorrente "de interesses e circunstâncias socialmente condicionadas. Essa escolha é fruto de determinada inserção do pesquisador na sociedade. O olhar sobre o objeto está condicionado historicamente pela posição social do cientista e pelas correntes de pensamento existentes".

Sendo assim, torna-se imprescindível a definição, num primeiro momento, daquilo que será estudado - objeto de estudo - para posteriormente optar-se pela abordagem metodológica. É bem verdade que algumas pessoas, ao desenvolver um estudo escolhem primeiro a metodologia ou o referencial metodológico (por identificação, ou talvez porque esteja "na moda") e, posteriormente, procuram ajustar o objeto selecionado àquela abordagem. Dessa maneira, tornam bem complicado o desenvolvimento do estudo, uma vez que o processo é inverso, ou seja, é o assunto seleconado que determina o método mais adequado para que os objetivos possam ser alcançados.

Ao proceder a escolha do objeto de investigação, na minha tese de doutorado, procurei seguir as recomendações dos autores supracitados e elegi um tema de meu interesse, com o qual tenho grande afinidade e, de certa maneira, vivencio em meu cotidiano como mulher, mãe e trabalhadora de enfermagem. Embora a literatura a respeito da mulher seja bem vasta, a abordagem da mulher na enfermagem e sua experiência na maternidade, nem tanto, o que permitiu o ineditismo da execução de uma tese e o aprofundamento na temática. Em virtude do objeto selecionado, um caminho emergiu, qual seja, a pesquisa qualitativa que possibilitaria um mergulho profundo nas nuances e particularidades que o tema comporta.

A pesquisa qualitativa preocupa-se com uma realidade que não pode ser quantificada, respondendo a questões muito particulares, trabalhando um universo de significados, crenças, valores e que correspondem a um espaço mais profundo das relações, dos fenômenos que não podem ser reduzidos à operacionalização de variáveis ${ }^{(3)}$.

Assim, conforme o objeto selecionado, a pesquisa qualitativa era a abordagem metodológica mais adequada, pois permite captar as singularidades do estudo. Das abordagens qualitativas, a mais apropriada era a História de Vida.

Nesse apanhado, faremos o relato de como o pesquisador deve "descer de seu pedestal" (4) ao realizar uma pesquisa (nas entrevistas e no próprio procedimento do estudo) para que seus resultados exprimam o mais próximo possível do que de fato as pessoas queiram expressar e que o estudo possa revelar.

Essas reflexões, portanto, revelarão alguns percalços do pesquisador ao realizar um estudo, especialmente, se não tem domínio da abordagem metodológica que e como pode/deve fazer para impedi-los e/ou corrigi-los, se porventura surgirem.

\section{A HISTÓRIA DE VIDA NA PESQUISA QUALITATIVA}

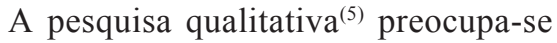
com os indivíduos e seus ambientes em suas complexidades, não havendo limites ou controle impostos pelo pesquisador. Desse modo,

baseia-se na premissa de que os conhecimentos sobre os indivíduos só são possíveis com a descrição da experiência humana, tal como ela é vivida e tal como ela é definida por seus próprios atores ${ }^{(5)}$. 
Assim sendo, uma investigação que priorize a informação do entrevistado exige uma aproximação do pesquisador com os pesquisados para que se estabeleça um contato, uma relação de confiança. Essa modalidade de pesquisa tem no ambiente a fonte direta dos dados e o pesquisador como seu principal instrumento ${ }^{(6)}$. É caracterizada pela obtenção de dados descritivos, no contato direto do pesquisador com a situação estudada, valorizando-se mais o processo que o produto, preocupando-se em retratar a perspectiva dos participantes, isto é o significado que eles atribuem às coisas e à vida. Dessa forma, são percebidos como as pessoas mais importantes no processo .

A história de vida é uma das modalidades de estudo em abordagem qualitativa. $\mathrm{O}$ termo História de Vida, traduzido de historie (em francês) e de story e history (em inglês), tem significados distintos ${ }^{(7)}$. O sociólogo americano Denzin propôs, em 1970, a distinção das terminologias: life story (a estória ou o relato de vida) é aquela que designa a história de vida contada pela pessoa que a vivenciou. Nesse caso, o pesquisador não confirma a autenticidade dos fatos, pois o importante é o ponto de vista de quem está narrando. Quanto à life history (ou estudo de caso clínico), compreende o estudo aprofundado da vida de um indivíduo ou grupos de indivíduos. Inclui, além da própria narrativa de vida, todos os documentos que possam ser consultados, como dossiês médico e jurídico, testes psicológicos, testemunhos de parentes, entrevistas com pessoas que conhecem o sujeito, ou situações em estudo $^{(7)}$. Assim, a história de vida trabalha com a estória ou o relato de vida, ou seja, a história contada por quem a vivenciou.

No relato de vida o que interessa ao pesquisador

é o ponto de vista do sujeito. O objetivo desse tipo de estudo é justamente apreender e compreender a vida conforme ela é relatada e interpretada pelo próprio ator ${ }^{(8)}$.

Assim, o método de história ou relato de vida "tem como conseqüência tirar o pesquisador de seu pedestal de "dono do saber" e ouvir o que o sujeito tem a dizer sobre ele mesmo:o que ele acredita que seja importante sobre sua vida" ${ }^{(8)}$.

Por meio do relato de Histórias de Vida individuais, podemos caracterizar a prática social de um grupo. Assim, "toda entrevista individual traz à luz direta ou indiretamente uma quantidade de valores, definições e atitudes do grupo ao qual o indivíduo pertence"(8). O método de história de vida, portanto, procura apreender os elementos gerais contidos nas entrevistas das pessoas, não objeti-vando, contudo, analisar suas particularidades históricas ou psicodinâmicas ${ }^{(8)}$. Nesse sentido,

histórias de vida, por mais particulares que sejam, são sempre relatos de práticas sociais: das formas com que o indivíduo se insere e atua no mundo e no grupo do qual ele faz parte ${ }^{(7)}$.

Uma narrativa tem uma função descritiva e avaliadora $^{(8)}$ pois, quando relatamos um fato, na verdade, estamos tendo oportunidade de refletir sobre aquele momento. Uma vez que "o sujeito não relata simplesmente sua vida, ele reflete sobre ela enquanto conta" ${ }^{(7)}$. Nessa abordagem, o pesquisador respeita a opinião do sujeito e acredita no que diz. Dessa forma,

quem faz a avaliação não é o pesquisador, e sim o sujeito (...) o pesquisador e o sujeito se completam e modificam mutuamente em uma relação dinâmica e dialética ${ }^{(8)}$.

O método de História de Vida ressalta o momento histórico vivido pelo sujeito. Assim esse método

\section{é necessariamente histórico (a tempora- lidade contida no relato individual remete ao tempo histórico), dinâmico (apreende as estruturas de relações sociais e os pro- cessos de mudança) e dialético ( teoria e prática são constantemente colocados em confronto durante a investigação) ${ }^{(9)}$.}

Destarte, possibilita o estudo sobre a vida das pessoas, penetrar em sua trajetória histórica e compreender a dinâmica das relações que estabelece ao longo de sua existência.

Autilização da História de Vida como abordagem metodológica vem evoluir continuamente. Foi introduzida no meio acadêmico, em 1920, pela Escola de Chicago e desenvolvida por Znaniescki, na Polônia. A partir da década de 60 , esse método de pesquisa procurou estabelecer as estratégias de análise do vivido, constituindo um método de coleta de dados do homem no contexto das relações sociais ${ }^{(10)}$.

Nesse sentido, o cotidiano das pessoas é retratado por meio de suas histórias de vida. $\mathrm{O}$ cotidiano é entendido como o momento em que
Trabalhando com a história de vida percalços de uma pesquisa(dora?) 
Thelma Spindola é recebido (pelos atores sociais) como o tempo/ espaço/ ação do idêntico sempre igual a si mesmo; e no entanto é também o concreto, o tempo e o espaço das ações que nos pertencem mais, a dimensão social mais investida de significação de desejos individuais, um campo que longe de ser uma repetição monótona parece carregado de férteis microeventos (11).

Segundo essa linha de pensamento, nosso cotidiano é repleto de significações: é um conjunto de situações vivenciadas no dia-adia, percebidas individualmente e renovando-se a cada instante. A vida cotidiana é caracterizada

como o lugar das negociações do acontecimento pelos seres humanos e, ainda, como o lugar de disposição da existência pela construção sempre renovada da interface da natureza e da cultura ${ }^{(12)}$

Um estudo do cotidiano ${ }^{(13)}$ dirige o olhar do pesquisador para uma dimensão, uma família , um grupo social que pode ser identificado pelas práticas sociais que elabora.

Relacionando o cotidiano e a narrativa de vida, os autores afirmam que

através das narrativas de sua vida, o indivíduo se preenche de si mesmo, se obrigando a organizar de modo coerente as lembranças desorganizadas e suas percepções imediatas: esta reflexão do si faz emergir em sua narração todos os microeventos que pontuam a vida cotidiana, do mesmo modo que as durações, provavelmente comuns aos grupos sociais, mas que dentro da experiência individual contribuem para a construção social da realidade ${ }^{(11)}$.

Nessa concepção concluiram que as histórias de vida não falam sozinhas sendo necessário enquadrá-las no contexto em que se desenvolvem, ou seja, avaliar todo um conjunto de significações que formam a vida cotidiana ${ }^{(11)}$.

O relato de vida foi empregado ${ }^{(8)}$, com o termo História de Vida, justificando-se pela conveniência de ser mais conhecido. Na enfermagem foi utilizado a partir da década de 90 , com os temas mais diversificados. Assim, vários autores utilizaram esse método, em seus estudos, conforme a experiência de trabalho e o objeto selecionado para investigação.

No estudo sobre as mães de crianças especiais $^{(14)}$ utilizou-se o método citado por per- mitir uma aproximação maior ao grupo pesquisado, possibilitando compreender qual o significado para uma mãe ter um filho especial .

O cliente renal crônico e sua adaptação à nova condição de vida foram analisados ${ }^{(15)}$ por meio dessa abordagem, considerando que a visão que o cliente tem de sua saúde é importante para uma assistência de enfermagem individualizada e holística .

A realidade de ser um transplantado renal foi descrita ${ }^{(16)}$ pelo emprego do método citado, captando-se a subjetividade dos relatos dos clientes e observando-se que essa abordagem trouxe benefícios para uma reflexão pessoal na atuação profissional.

Para retratar o olhar das mães de uma comunidade carente sobre o desenvolvimento de seus filhos, utilizou-se a História de $\operatorname{Vida}^{(17)}$. A pesquisa desmistificou a crença de que as mães faveladas não cuidam adequadamente de seus filhos e recomenda que os programas governamentais respeitem as necessidades individuais das comunidades, trazendo benefícios reais para as famílias.

A mulher portadora de doença sexualmente transmissível (DST) foi estudada ${ }^{(18)} \mathrm{com}$ utilização do referido método. O estudo evidenciou que as orientações educativas, fornecidas durante a consulta de enfermagem, contribuíram para a reflexão das clientes para assumir atitudes responsáveis frente à sua sexualidade e à própria vida.

Para compreender a percepção da mulher que toma conhecimento de que é soropositiva durante os exames de pré-natal, empregou-se a História de $\mathrm{Vida}^{(19)}$. Foi revelado que as gestantes associavam a Aids como doença do outro, além da necessidade de capacitação dos profissionais para que se trabalhem preconceitos, temores e possam prestar atendimento individualizado e específico à clientela.

As práticas obstétricas das parteiras tradicionais da Amazônia foram analisadas ${ }^{(20)}$ por este método de pesquisa. $\mathrm{O}$ estudo permitiu conhecer as práticas obstétricas e a terapêutica utilizadas pelas parteiras na assistência ao parto domiciliar, identificando-as como menos intervencionistas conforme a política de humanização do parto e nascimento do Ministério da Saúde. 
As investigações na enfermagem têm buscado uma maior aproximação do pesquisador com os sujeitos do estudo, procurando escutálos e não apenas tratá-los como simples objetos de uma pesquisa, numa relação impessoal e fria. Por isso têm utilizado a História de Vida como abordagem metodológica por permitir ainda estabelecer uma relação dialógica.

\section{A CARACTERIZAÇÃO DO CENÁRIO}

Os cenários das pesquisas que adotam o método da História de Vida, em geral, são diversificados, conforme o objeto de estudo. No caso específico da tese de uma das autoras, o cenário é o Hospital Geral Público do Município do Rio de Janeiro, tendo como sujeitos as profissionais de enfermagem do sexo feminino que têm filhos, condição exigida pelo objeto de estudo selecionado ( $\mathrm{O}$ cotidiano da Mulher, Mãe e Trabalhadora de Enfermagem).

Vale ressaltar, todavia que, na realização de qualquer pesquisa, deverão ser respeitadas as diretrizes e as normas regulamentadoras de pesquisas com seres humanos, estabelecidas pela Resolução 196/96 do Conselho Nacional de Saúde ${ }^{(21)}$. Ou seja, os participantes do estudo deverão ser informados dos objetivos e assinar um termo de consentimento, o qual deverá ser elaborado em duas vias, sendo uma entregue ao entrevistado.

Assim, procura-se, por meio dos relatos, apreender o cotidiano das pessoas, ou a opinião que têm sobre determinado aspecto de sua vida. Nesse sentido é ressaltado que:

\begin{abstract}
é através da análise das práticas diárias dos indivíduos que se pode chegar a uma compreensão da dinâmica da personalidade de uma pessoa, ou das características e atitudes de um grupo social ${ }^{(8)}$.
\end{abstract}

Para a obtenção dos relatos, uma das autoras aproximou-se das profissionais de enfermagem, explicitando os objetivos do estudo e convidando-as a participar dele. Com as mulheres que se interessaram foi realizada uma entrevista aberta com a questão: Fale-me de sua vida como mulher, mãe e trabalhadora de enfermagem . Foi utilizado o recurso de gravação em fita magnética (cassete), mediante prévia aquiescência das depoentes, visando garantir a fidedignidade daquilo que for dito, durante as entrevistas, e o anonimato.

A entrevista biográfica é sempre uma interação social ${ }^{(8)}$. Desse modo, revela que a situação de entrevista, por si só, determina, em grande parte, o discurso recoIhido, sendo que as formas e conteúdos da narrativa vão variar de acordo com o tipo de diálogo entre o sujeito e o interlocutor ${ }^{(8)}$.

Essa modalidade de entrevista, deve ser prolongada para permitir a interação constante entre pesquisador e informante ${ }^{(14)}$ e também para que "o interlocutor seja tomado pelo desejo de relatar e que ele próprio passe a conduzir a conversa" ${ }^{(7)}$.

A maneira como o sujeito será abordado deve ser do modo mais aberto possível, dizendo: Fale de sua vida e interferindo o mínimo possível ${ }^{(9)}$. Nesse sentido, é recomendado ${ }^{(7)}$ uma escuta atenta porém sem ser passiva. Assim, procurei ouvir os relatos das trabalhadoras de enfermagem, evitando interferir em suas falas, a não ser para esclarecer algum detalhe ou estimular o seu dizer. $\mathrm{Na}$ teoria, tudo pode parecer muito simples, todavia, na prática, nem sempre o é.

\section{O MOMENTO DAS ENTREVISTAS}

A obtenção dos relatos das profissionais de enfermagem teve início no $2^{\circ}$ semestre de 2000. Por ser uma das autoras enfermeira lotada no Hospital onde realizou-se o estudo, não teve dificuldade em se aproximar das depoentes. Inicialmente solicitou autorização à Superintendência de Enfermagem na pessoa do Diretor do Hospital que a autorizou a fazê-lo. De posse da autorização e com o formulário do Conselho Nacional de Saúde que dispõe sobre as pesquisas com seres humanos, aproximou-se das depoentes, expondolhes a proposta de trabalho. Deixava-as à vontade para participarem do estudo, entregando-lhes o Termo de Consentimento.

Explicava-lhes a importância do estudo e como poderiam colaborar. A adesão foi imediata. Todas ficam admiradas e felizes com o tema escolhido (mulher, mãe e trabalhadora de enfermagem) para a investigação e dispuseram-se a falar sem constrangimentos.

Realizou três entrevistas inicialmente, as quais considerou como uma aproximação entre a pesquisadora e o método adotado. Destas, a primeira teve 60 minutos de duração; a segunda e a terceira, em torno de 40 minutos. Como não dispunha de um local exclusivo para a realização das entrevistas, e só podia conversar com as entrevistadas em seu ambi-
Trabalhando com a história de vida percalços de uma pesquisa(dora?) 
Thelma Spindola

Rosângela da Silva Santos (a) Comentário da Dra Rosângela da Silva Santos na disciplina eletiva: Métodos Qualitativos da Pesquisa: Abordagem História de Vida. Curso de Doutorado em Enfermagem. EEAN/UFRJ

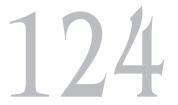

Rev Esc Enferm USP 2003; 37(2): 119-26. ente de trabalho (para que ocorresse em outro local, seria necessária maior disponibilidade de tempo das entrevistadas, o que geralmente não existe) sempre buscou um local reservado. A primeira entrevista ocorreu em uma sala destinada à administração do setor, no próprio local de trabalho, onde ficaram trancadas, sendo interrompidas por duas vezes. Com a segunda, ficaram em seu próprio setor, na sala do café. Foram, também, interrompidas duas vezes, mas o relato foi bem tranqüilo. A terceira entrevistada deu o seu depoimento em sua sala de trabalho, porém não houve interrupções. Apesar de as interrupções não terem prejudicado o relato, de certo modo, elas desconcentram as depoentes. O ideal, então, é que possam se expressar sem serem interrompidas, mesmo porque, em muitos momentos, as entrevistadas emocionam-se, choram, sendo importante a manutenção de privacidade nessas ocasiões.

À medida que as entrevistas iam acontecendo foram sendo transcritas. Essa etapa pode ser realizada pelo próprio pesquisador ou delegada a outra pessoa. Em geral, alguns pesquisadores, devido à escassez de tempo, costumam solicitar que alunos bolsistas ou outras pessoas realizem essa tarefa. Quando o próprio pesquisador transcreve as fitas, o momento se torna propício para maior aproximação dos sujeitos e aprofundamento no objeto da pesquisa. Por outro lado, vale considerar que há necessidade de o pesquisador dispor de tempo para proceder as transcrições. Em geral, as entrevistas abertas são longas o que demanda uma certa articulação com outros compromissos que porventura possam interferir na transcrição dos relatos.

As entrevistas iniciais (três) serviram como ambientação à técnica proposta pelo método, ou seja, a entrevista com questão aberta. A pesquisadora que coletava os dados sentiu dificuldade em manter-se calada no decorrer do procedimento. Assim, interrogou-as, durante seus relatos, o que é incorreto conforme o procedimento adotado. Essas entrevistas, então, serviram de base para sua adaptação e correção. Essa postura é característica típica dos profissionais de enfermagem, os quais, por natureza, são intervencionistas e, a todo momento, sentem-se impelidos a interagirem com a clientela, segundo sustenta a própria orientadora do estudo ${ }^{(a)}$.

É interessante salientar que a pesquisa foi bem aceita pelas depoentes e que a pesquisadora tem sido abordada por demais tra- balhadoras para averiguar se podem compor o grupo de pesquisa, o que tem causado grande satisfação. Por outro lado, vale destacar que as entrevistadas sentem-se tão tranqüilas, durante o relato, que não percebem o quanto falaram, fato notado, por nós, no momento das transcrições. Ressalta-se também, a difícil atitude de ouvinte do pesquisador não podendo interferir e nem opinar durante os relatos. Embora seja salientado ${ }^{(7)}$ que a entrevista é um momento de escuta atenta, sem ser passiva, destacamos que essa é a parte mais complicada e que só percebemos que a autora que coletou os dados não procedeu de acordo com o método quando ouvimos a fita.

Todavia, para minimizar a possível ansiedade e expectativa em relação ao não dito é possível lançar mão de mais perguntas para apresentar caso não abordem aspectos que o pesquisador acredite serem relevantes ${ }^{(8)}$. Entretanto caso necessite de algum esclarecimento maior, pode-se solicitar à depoente que fale mais sobre algum aspecto que não ficou esclarecido e clarificar as informações a respeito do assunto ${ }^{(7)}$. No caso do estudo que estamos realizando, esse procedimento está sendo adotado e temos utilizado questões esclarecedoras somente como última opção.

Pensamos ser muito importante a relação de confiança que se estabelece entre entrevistado e entrevistador, sendo um momento mágico de exteriorização de sentimentos, emoções, angústias, mágoas, como se fizessem uma catarse. É o que temos sentido, até então. Todavia, ressaltamos ser extremamente difícil ouvir relatos tão verdadeiros e cheios de emoção e, ao mesmo tempo, conter a ansiedade para intervir e interrogar as entrevistadas. Esta atitude, por outro lado, acaba interferindo nos relatos, na espontaneidade e impede-as de conduzir as entrevistas conforme o método adotado estabelece. E é baseado nesse procedimento que passei a conduzir as entrevistas que se seguiram.

Admitimos que não foi uma tarefa das mais fáceis. É difícil calar. Nós, enfermeiros, somos treinados para falar, interagir e intervir com a comunidade. Sempre temos algo a dizer. Quando precisamos apenas ouvir, sem fazer comentários, observamos o quanto falamos. E como essa atitude interfere nas respostas que obtemos. Tive a oportunidade de comparar as entrevistas iniciais com as que 
se seguiram - Que diferença! É a voz do sujeito que queremos (e precisamos) ouvir! É a história deles que vamos relatar, não a nossa. Nossas impressões aparecerão, sim, no momento da análise. Na ocasião das entrevistas, é a voz dos entrevistados que precisa ser ouvida. De certa maneira, a entrevista com pergunta aberta, utilizada no método da História de Vida, mostrou-nos que a entrevistadora não escutava as pessoas, ou melhor, não sabia ouví-las sem interferir, sem emitir a própria opinião a respeito. $\mathrm{Nem}$ sempre as pessoas querem ouvir alguma opinião, às vezes, só querem falar e que alguém as escute. Esse é um cuidado que merece a atenção do pesquisador, quando elege a História de Vida como metodologia a ser utilizada no estudo.

\section{A ANÁLISE - CAMINHOS PARA O PESQUISADOR}

O número de relatos a ser colhidos depende da qualidade das informações obtidas. Desse modo, a coleta dos depoimentos só é encerrada à medida que estes atinjam o ponto de saturação, ou seja, comecem a se tornar repetitivos ou não acrescentem fatos novos aos relatos anteriormente obtidos ${ }^{(7)}$.

A análise dos relatos inicia-se tão logo começam as transcrições das fitas magnéticas, procedimento esse que se inicia imediatamente após as primeiras entrevistas, o que facilita a avaliação do procedimento metodológico, criando possibilidades de ajustes no processo, no caso de incorreções, bem como direciona o caminhar do pesquisador. Os relatos são lidos e relidos, quantas vezes se fizerem necessários para a apreensão das categorias emergentes das falas das entrevistadas.

\begin{abstract}
Assim,
a atenção prestada à transcrição se torna então um aspecto essencial da análise que se segue: a relação da entrevista é organizada em três pontos diferentes e interdependentes: o primeiro reproduz por escrito o texto do registro; o segundo descreve a estrutura (frame) de interação tal como foi instaurada no curso da entrevista; o terceiro consiste na interpretação obtida do cruzamento do primeiro com o segundo(11).
\end{abstract}

Até o momento, realizamos 23 entrevistas. Os relatos estão impregnados de emoção, sentimentos, sendo a ocasião em que as mulheres revelam suas expectativas, frustrações, esperança e crenças. Na ocasião de transcrição das entrevistas temos oportunidade de relembrar o momento do encontro e a emoção que ele comporta, que, muitas vezes, fica contida nas entrelinhas, no não dito, nas palavras entrecortadas por lágrimas e silêncio. A postura do entrevistador de respeito, cumplicidade e até mesmo, em algumas situações, chegando a se emocionar diante das falas contribui para a riqueza das informações obtidas. É um momento de extrema sensibilidade em que as emoções afloram.

O sujeito reflete sobre a sua vida enquanto $\operatorname{conta}^{(7)}$. Assim, quando fazemos o relato de um fato, estamos tendo oportunidade de refletir sobre aquele momento ${ }^{(4)}$. É essa relação que temos percebido durante os relatos. As pessoas estão refletindo sobre suas vidas e analisando-as enquanto contam. Muitas têm solicitado para relatarem mais a respeito, sendo esse um momento em que param para refletir e encontram alguém disposto a escutá-las - o pesquisador.

O método de História de Vida é, portanto, muito interessante para o desenvolvimento de pesquisas na área da enfermagem, garantindo uma aproximação entre os sujeitos da pesquisa e o pesquisador. A própria maneira de interagir com o ambiente de trabalho, em muitas situações, se transformará, após o encontro. Esse fato está ocorrendo conosco e ocorreu com outros ${ }^{(16-17)}$, revelando a propriedade dessa abordagem para o desenvolvimento de estudos em que se priorize a relação dialógica entre os sujeitos.

A realização de pesquisas em enfermagem, utilizando o método de História de Vida, tem evidenciado que o profissional que atua na assistência não deve apenas priorizar o desenvolvimento das técnicas e o domínio do conhecimento técnico-científico. Há que se preocupar, atualmente, também com a subjetividade nas relações entre profissionais e sujeitos.

A inclusão da dimensão subjetiva no cuidado é uma necessidade atual para que o profissional da área da saúde, em especial, a enfermeira, estabeleça uma relação efetiva com os sujeitos dos serviços de saúde, implementando procedimentos terapêuticos que priorizem os aspectos psíquicos, o acolhimento e a humanização da assistência.

Há que se substituir um cuidado centrado na doença para um cuidado centrado na pessoa. O profissional da área da saúde ainda apresenta atitudes normativas e prescritivas. Há
Trabalhando com a história de vida percalços de uma pesquisa(dora?) 
Thelma Spindola Rosângela da Silva Santos que se ampliar o conceito de cuidar com vistas à obtenção da promoção da saúde sem, no entanto, recair na dicotomia preventivo/curativo, integral/fragmentado e atender as necessidades da clientela. E para atender as necessidades da clientela é preciso aprender a ouvir o que ela tem a falar. Somos eficientes, competentes e sabemos as providências que devem ser tomadas nas diferentes situações. Será, no entanto, que conseguimos atender ao desejo da clientela? Será que o que estabelecemos é o que a cliente gostaria que fosse feito? Estamos dando voz a cliente? Temos tempo para ouvir o que ela está querendo ou determinamos o que ela provavelmente quer?

\section{REFERÊNCIAS}

(1) Eco U. Como se faz uma tese. $13^{a}$ ed. São Paulo: Perspectiva; 1996.

(2) Goldenberg M. A arte de pesquisar: como fazer pesquisa qualitativa em Ciências Sociais. $3^{\mathrm{a} e d . ~ R i o ~ d e ~ J a n e i r o / ~ S a ̃ o ~ P a u l o: ~ R e c o r d ; ~} 1999$.

(3) Deslandes SF, Cruz Neto O, Gomes R, Minayo MCS. organizadores. Pesquisa social: teoria, método e criatividade. $7^{\mathrm{a}} \mathrm{ed}$. Petrópolis/ Rio de Janeiro: Vozes; 1994.

(4) Glat R. Ser mãe e a vida continua. $2^{\mathrm{a} e d}$. Rio de Janeiro: Agir; 1994.

(5) Polit DF, Hungler BP. Fundamentos de pesquisa em enfermagem. $3^{\mathrm{a}}$ ed. Porto Alegre: Artes Médicas; 1995.

(6) Ludke M, André MEDA. Pesquisa em educação: abordagens qualitativas. São Paulo: EPU; 1986.

(7) Bertaux D. L'approche biographique: sa valité méthodologique,ses potentialités. Cahiers int sociol 1980; 69: 197-225.

(8) Glat R. Somos iguais a vocês: depoimentos de mulheres com deficiência mental. Rio de Janeiro: Agir; 1989.

(9) Brioschi LR, Trigo MHB. Relatos de vida em ciências sociais: considerações metodológicas. Ciênc e Cult 1987; 39 (7): 631-7.

(10) Chizotti A. Pesquisa em ciências humanas e sociais. São Paulo: Cortez; 1991.

(11) Cipriani R, Pozzi E, Corradi C. Histoires de vie familiale dans un contexte urbain. Cahiers int sociol 1983; 79: 253-62.

(12) D'Epinay CL. La vie quotidienne (Essai de construction d'un concept sociologique et anthropologique) Cahiers int sociol 1983; 74: 13-37.
Essas questões estão surgindo à medida que aumenta o número de pesquisas desenvolvidas por esse método. Podemos, então, perceber a dificuldade de a enfermeira simplesmente ouvir a clientela, sem que essa ação seja acompanhada de uma outra, definida pela profissional, que, na maioria das vezes, é o que ela entende como ideal para a cliente e, nem sempre (ou na maioria das vezes?) é aquilo que a cliente gostaria (mas é o que tem que ser feito), estabelecido "a priori" e pautado em aspectos gerais e teóricos.

E por último, questionamos: será que a enfermeira está descendo de seu pedestal e dando voz ao sujeito desse cuidado?
Recebido: 05/03/2001 Aprovado: 11/07/2003

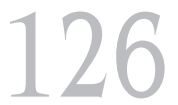

Rev Esc Enferm USP 2003; 37(2): 119-26.
(13) Rezende ALM. Quotidiano e saúde. In: Rezende ALM, Ramos FRS, Patrício ZM. organizadores. O fio das moiras - o afrontamento do destino no quotidiano da saúde. Florianópolis: UFSC; 1995. p.9-15.

(14) Santos RS. Ser mãe de uma criança especial : do sonho à realidade. [tese] Rio de Janeiro (RJ): Escola de Enfermagem da UFRJ; 1995.

(15) Silva MGAA. O cliente renal crônico e sua adaptação à nova condição de vida. [dissertação] Rio de Janeiro (RJ): Escola de Enfermagem da UFRJ; 1996.

(16) Assad LG. Entre o sonho e a realidade de ser transplantado renal. [dissertação] Rio de Janeiro (RJ): Escola de Enfermagem da UFRJ; 1997.

(17) Santos IMM. O olhar da mãe sobre o desenvolvimento de seu filho no contexto de sua história de vida. [dissertação] Rio de Janeiro (RJ): Escola de Enfermagem da UFRJ; 1998.

(18) Gonçalves LRR. A mulher portadora de doença sexualmente transmissível: compartilhando sua vivência na consulta de enfermagem. [dissertação] Rio de Janeiro (RJ): Escola de Enfermagem da UFRJ; 1999.

(19) Ribeiro MGM. Gestante HIV positivo: a história de vida contribuindo para a assistência de enfermagem. [dissertação] Rio de Janeiro (RJ): Escola de Enfermagem da UFRJ; 2000.

(20) Chamilco RASI. Práticas Obstétricas adotadas pelas parteiras tradicionais na assistência ao parto e nascimento domiciliar na Amazônia Legal Santana, AP. [dissertação] Rio de Janeiro (RJ): Escola de Enfermagem da UFRJ; 2001.

(21)Conselho Nacional de Saúde. Fundação Oswaldo Cruz. Resolução 196/96 de 10 de outubro de 1996. Diretrizes e normas regulamentadoras de pesquisas envolvendo seres humanos. Brasília: Fiocruz; 1996. 